Article

\title{
Understanding the Concept of Neighbourhood in Kigali City, Rwanda
}

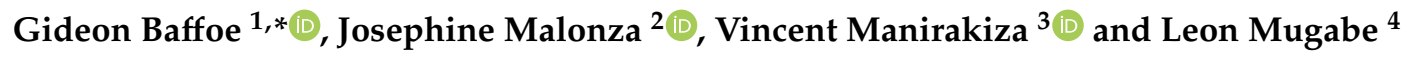 \\ 1 Centre for Sustainable, Healthy and Learning Cities and Neighbourhoods (SHLC), Urban Studies, School of \\ Social and Political Sciences, University of Glasgow, Room 710 Adam Smith Building, 40 Bute Gardens, \\ Glasgow G12 8RS, UK \\ 2 School of Architecture and the Built Environment, College of Science and Technology, University of Rwanda, \\ Kigali P. O. Box 4285, Rwanda; josemwongeli@yahoo.com \\ 3 College of Education-Geography, University of Rwanda, Kigali P. O. Box 4285, Rwanda; \\ vmanir3@gmail.com \\ 4 College of Education-Social Sciences, University of Rwanda, Kigali P. O. Box 4285, Rwanda; \\ rwema36@yahoo.fr \\ * Correspondence: Gideon.Baffoe@glasgow.ac.uk
}

Received: 21 January 2020; Accepted: 13 February 2020; Published: 19 February 2020

check for updates

\begin{abstract}
Though the relevance of the concept of neighbourhood in both research and policy oriented circles is unquestionable, the concept remains contested and fluid, making its operationalisation a daunting task, particularly in practice. This study explores how the concept of neighbourhood has been operationalised in Kigali city and how the neighbourhood boundaries and typologies are defined. The paper dwells on the review of relevant literature, interviews with 25 practitioners and field observations. It is argued that neighbourhood conceptualisation in Kigali is both theory-it bears the common aspects of neighbourhood definitions-and practice driven, reflecting modernity and context. On the one hand, modernity suggests the desire of planning authorities to follow contemporary planning practices. Context, on the other hand, reflects the desire to tailor local policies to country specific challenges. While boundaries follow subjective, administrative and physical models, typologies tend to be overly physical, focusing mainly on housing structures. The study identified three conventional neighbourhood typologies - planned, informal and mixed types. Given the predominance of informal and mixed neighbourhoods, this study further argues that such areas form the 'bedroom' and 'transit point' for most lower- and middle-class workers, in addition to serving as a 'laboratory' for testing various social interventions. The study recommends a well-serviced mixed classification typology to foster a strong sense of belongingness.
\end{abstract}

Keywords: urbanisation; neighbourhood; boundary; typology; Kigali

\section{Introduction}

Rapid urbanisation has increasingly become a major developmental problem, particularly in developing countries. The global urban population has grown from 751 million in 1950 to 4.2 billion in 2018, and it is projected to increase further to 6 billion by 2050 [1,2]. Highly urbanised regions include Northern America (82\% living in urban areas), Latin America and the Caribbean (81\%), Europe (74\%) and Oceania (68\%). Although Africa remains the least urbanised region, with $43 \%$ of its population living in cities [1], it is currently urbanising at a faster pace. The continent's urban population is estimated to more than triple in the next 40 years, reaching 1.339 billion in 2050, corresponding to $21 \%$ of the world's projected urban population [3]. Consequently, scholars have described Africa's urban growth as atypical $[4,5]$. 
Urbanisation does not happen in a silo, as it is usually accompanied by intricate challenges, including but not limited to, incessant demand for affordable housing, transport networks, basic services and jobs [6]. Even in areas where urbanisation is occurring at a slower pace, its ramifications, such as environmental degradation and social segregation remain unabated [7]. The deficit in affordable housing is particularly worrying. It is estimated that almost 1 billion people (most in developing countries) live in informal settlements [6] without access to basic amenities, for instance, potable water and toilet facilities as well as health and education services. In most parts of the world, attempts to uplift the image of informal settlements have resulted in inconsistent livelihood policies [8] and drastic eradication measures [9], which [8] describes as a sign of capitalism-putting productivity ahead of quality of life. These seem to put forward the economic and political dimensions of housing way above the social and cultural dimensions. The situation is especially the case in Africa, where urban development is taking place at the expense of economic improvement. Inequality has become rampant, with urban wealth and productive jobs concentrated in the hands of a few elites. Major livelihoods, particularly among the majority poor, remain strikingly insecure and vulnerable [10]. In particular, spatial inequality is manifested through recent housing development processes that have largely concentrated on gated communities, peri-urban expansion and slum re-development [11,12].

Rwanda, the most densely populated country in Africa, has been feeling the pinch of urbanisation in recent decades. Rising informal neighbourhoods, a direct consequence of urbanisation, largely result from market forces in the inner city. Low-income earners are constantly pushed out of Kigali city centre because of the high cost of living [13]. In 2016, it was estimated that over 340,000 housings units would be needed to serve the rising urban dwellers by 2022 [14]. Meanwhile, the desire to survive at all costs in Kigali has precipitated the development of many informal enclaves, where housing structures are of poor quality [15]. Existing neighbourhoods are characterised by the lack of improper waste and sanitation facilities as well as limited space and undulating landscape [15].

Over the past two decades, attempts to modernize Kigali city have seen many informal settlements expropriated [16] in the name of public interest. Strict planning measures, including implementation of the 2013 City Master Plan [17] are also in operation. Given the recent spatial development and reputation as the fastest growing city in Africa, the question that this paper seeks to answer is: to what extent has the concept of neighbourhood has been operationalised in Kigali city? This study is especially relevant because Rwanda has attracted little attention from scholars working in the domain of cities and urbanisation [18]. To date, little has been done to understand the internal dynamics of Kigali city. In particular, the boundaries of residential areas are still blurred, due to the lack of scientific evidence. This has inhibited understanding on how Kigali neighbourhoods are created and shaped. The present study, in addition to contributing to the current efforts to empirically operationalize the neighbourhood concept, will also add to our current knowledge on Kigali city. Importantly, the attempt to link theory to practice is especially relevant in the sense that it speaks directly to bridging the dichotomy between the two. This study uses mixed qualitative methods, including a review of relevant literature from diverse sources (such as journal articles, policy documents, newspapers and books), interviews with practitioners and field observations.

The structure of this study is as follows. Section 2 provides theoretical perspectives on the conceptualisation of neighbourhoods. Section 3 presents the study area and methodology. Section 4 focuses on results, followed by discussions in Section 5. Section 6 concludes this study with recommendations.

\section{Theoretical Perspectives on the Concept of Neighbourhood}

The concept of neighbourhood has not been static; it has seen evolution in recent decades. A recent article [19] traced the origin of the concept to two major disciplines-planning and anthropology. The concept has emerged strongly as a variable in both research and policy units, but its exact meaning remains contested among scholars [19]. The next section looks at how the concept has been constructed by scholars. 


\subsection{Defining Neighbourhood}

The concept of neighbourhood remains hotly debated. To date, there is no agreed definition. It has been defined variously as a place, a community and as a policy unit [19]. The EU, as cited in [20], for instance, defines neighbourhood as a physical space with complex interactions existing between different activities and actions, which collectively form the living environment for the inhabitants. Ref. [21] defines neighbourhood as a collection of people who are commonly identified by shared services and social cohesion in a geographically bounded space. Ref. [19] adds that a neighbourhood is an area where people reside and spend most of their time. From these definitions, it could be seen that elements of space, people, interactions and activities, collectively shape a neighbourhood landscape. Analytically, the varied connotations make application daunting [22].

The distinction between neighbourhood as a place and as a community remains fluid. According to [19], the difference lies within their boundaries; while communities may have defined boundaries, many neighbourhoods (as a place) may not have these, because neighbourhoods can be subjectively constructed with no definite order, but with identifiable attributes such as race, job or religion. Geographically delineated neighbourhoods as communities are prevalent in urban areas in modern society because such areas are easily identifiable, given their geographically demarcated borders, which make data collection and accessibility for research purposes relatively easier [19]. According to [19], "given that neighbourhoods are lower units, and subjectively created in most cases, data generation remains ad hoc, unlike in communities, where the boundaries can serve as a guide for sampling purposes". Ref. [19] adds that neighbourhoods as communities are often more formal and particularly critical for urban governance and management system, as the official boundaries provide impetus for decentralisation of administrative functions. It is worth noting that a neighbourhood transformation or transition is possible through an act of reclassification. According to [23], a neighbourhood as a place, for instance, can be reclassified as a community if given official recognition either by physical or administrative boundaries.

A fundamental truth is that neighbourhood defies singular definition. The concept has also been defined from planning and policy perspectives, with the fundamental goal being to foster inclusiveness in decision-making processes. Ref. [19] explained that "the desire by governments and donor agencies to effectively redistribute limited resources across space also influences neighbourhood creation. The actions usually result in cluster typologies (for resource distribution purposes). Such neighbourhoods tend to be subjective in nature, as they are characterised by special attributes (e.g., race, housing type and/or economic activity). They are particularly evident in informal settlements in developing countries, where service provision usually lacks any defined pattern". A key attribute of such neighbourhoods is the ad hoc nature by which they are created. In the next section, this study looks at how the boundaries of neighbourhoods are defined.

\subsection{Defining Neighbourhood Boundary}

Scholars' attempts to enrich neighbourhood understanding have resulted in several boundary models. A "neighbourhood boundary is a border to protect encroachment from outside, to unite residents residing in, and to create places for transactions with surrounding functions", as cited in [21]. A neighbourhood may be defined by physical boundaries such as waterways or highways or by administrative boundaries, such as Census areas or tracts [23]. The physical boundary models form the basis of the work of city planners and urban designers [24]. Though the official delineation is well acknowledged and applied [25], some scholars believe that neighbourhoods are largely social productions, e.g., refs. [26,27]. The social production school of thought, however, has been criticised on the grounds that it is inaccurate and biased, and overly subjective. This notwithstanding, it continues to garner traction and favour in neighbourhood and community studies [28,29]. In the subjective definition of a neighbourhood, various features, including demographics (e.g., age, race, sex) and physical and natural characteristics (e.g., landmarks, farmlands, streets and rivers) are used [21]. The conceptualisation of spatial units tends to be subjective because they are usually not characterised 
by official physical or administrative boundaries. Such areas are often vernacular in nature, and hence, indistinct [30]. Therefore, the subjective boundary definition particularly becomes imperative in situations where limited resources have to be distributed. In this perspective, subjective demarcations become important for planners to divide a region for the purposes of resource allocation. These arbitrary divisions, it is noted, sometimes become official neighbourhoods even when the urban area undergoes rapid transformation [30].

In the real world, however, neighbourhoods largely exhibit mixed features, reflecting the complexity of human society. While neighbourhoods may transition from one type to another [31], they may be non-functional (unable to perform their core function), mono-functional (perform only one function) or multifunctional (perform multiple functions) [32] in nature. According to [33], the challenge in delineating precise measures of neighbourhood often leaves scholars at the crossroads. On the one hand, views of neighbourhood grounded in individual cognition and collective sentiments have had little operational content since they have not been employed in the specification of boundaries. On the other hand, views of a neighbourhood as a spatial unit defined by clear administrative boundaries have had no necessary correspondence with realities on the ground.

Clearly, delineating neighbourhood boundaries remains a major challenge in neighbourhood research and practice [21]. This, coupled with the disparate narratives, give impetus to empirical operationalisation of the concept. Relating the above constructs to the case of Kigali would be critical in empirically understanding the practical operationalisation of the concept. The next section looks at theoretical perspectives on neighbourhood typologies.

\subsection{Neighbourhood Typologies}

The definitional and neighbourhood boundary struggles, coupled with the advent of advanced statistical techniques such as cluster analysis, provide a practical approach to develop neighbourhood typologies. The typologies can be classified as subjective (e.g., health, race and class), administrative (e.g., census tracts) and physical (e.g., housing situation, nature of transport networks) neighbourhoods [34]. The study of [35] provides a good example. Using public data at the census block level in the United States, the authors created urban neighbourhood typologies sharing distinctive combinations of natural, built, and social structures. This typology offered a conceptual and empirical basis to develop hypotheses while designing studies of complex urban water systems.

In many urban settings, physical typologies, particularly based on housing conditions, tend to dominate. This is especially the case as policy makers try to contain issues of foreclosure, with the ability of policy makers and estate developers to distinguish neighbourhoods based on foreclosure risk and financial soundness of residents determining how well they are able to develop context-specific responses [34]. For subjective typologies, the case of health is of great importance to public health. Classifying neighbourhoods based on health enables health officials not only to identify contextual factors affecting health, but also to make educated decisions on prevention and treatment issues, in addition to informing the work of planners in the areas of land use and infrastructure development for behavioural change [34].

Within the typologies is neighbourhood hierarchy, which according to [21] can be grouped into four, on the basis of physical attributes (e.g., size, local facilities, and recognised boundaries), composition of socioeconomic features (e.g., homogeneity/heterogeneity of income, life cycle, and ethnicity), and the degree of informal network [21]. The first level is the face block-the smallest unit, which refers to a cluster of houses with close bond and strong informal and personal relationships. The second level is a residential neighbourhood, comprising several face blocks, which are homogenous in terms of physical and socioeconomic characteristics. They are mainly residential areas with similar street design and architecture. The third level is an institutional neighbourhood, made up of several residential neighbourhoods with a range of functions, including schools, health centres, recreational and social facilities, and shopping centres. Such areas may have an official or an administrative boundary [21]. The fourth level is a community, which is a cluster of districts of a city like a townships or suburbs. 
This category covers larger areas, extending sometimes to a whole city [21]. The next section presents the context.

\section{Study Area and Methodology}

Context, method and theory are all fundamental building blocks for any research project. This paper adopts the case study approach to capture the historical, social and physical settings of neighbourhoods in Kigali. This section presents an overview of the process of urbanisation in Kigali, status of the urban land use and the urban policies that have shaped the (trans)formation of the city.

\subsection{Contextualising Kigali City}

\subsubsection{Process of Urbanisation}

Prior to independence in 1962, the city of Kigali mainly hosted administrative functions. Given the commercial traction at the time, however, Kigali expanded from 2.5 to $112 \mathrm{~km}^{2}$ in size between 1962 and 1990. After the 1994 genocide, Kigali has continued to experience rapid growth, largely attributed to internal migration, natural increase and the influx of repatriated refugees from neighbouring countries. Extensive administrative reforms of 2000 and 2005 extended the city boundaries from 314 to $730 \mathrm{~km}^{2}$ [36]. Currently, the city is divided into three administrative districts (Figure 1)—Gasabo, Kicukiro and Nyarugenge, and three spatial patterns, consisting of the urbanised, the area under urbanisation and the urban fringe [37]. The topography of the city is characterised by hilly landscape, sprawling across four ridges and separated from one other by large valleys [37]. The lower part of the city has an elevation of about $1400 \mathrm{~m}$, compared to $1850 \mathrm{~m}$ in the higher hills [37]. Wetlands form another major feature of the landscape, covering nearly $13 \%$ of the city's total area. The wetlands play an important role in storing and releasing water and buffering the impacts of floods [36].

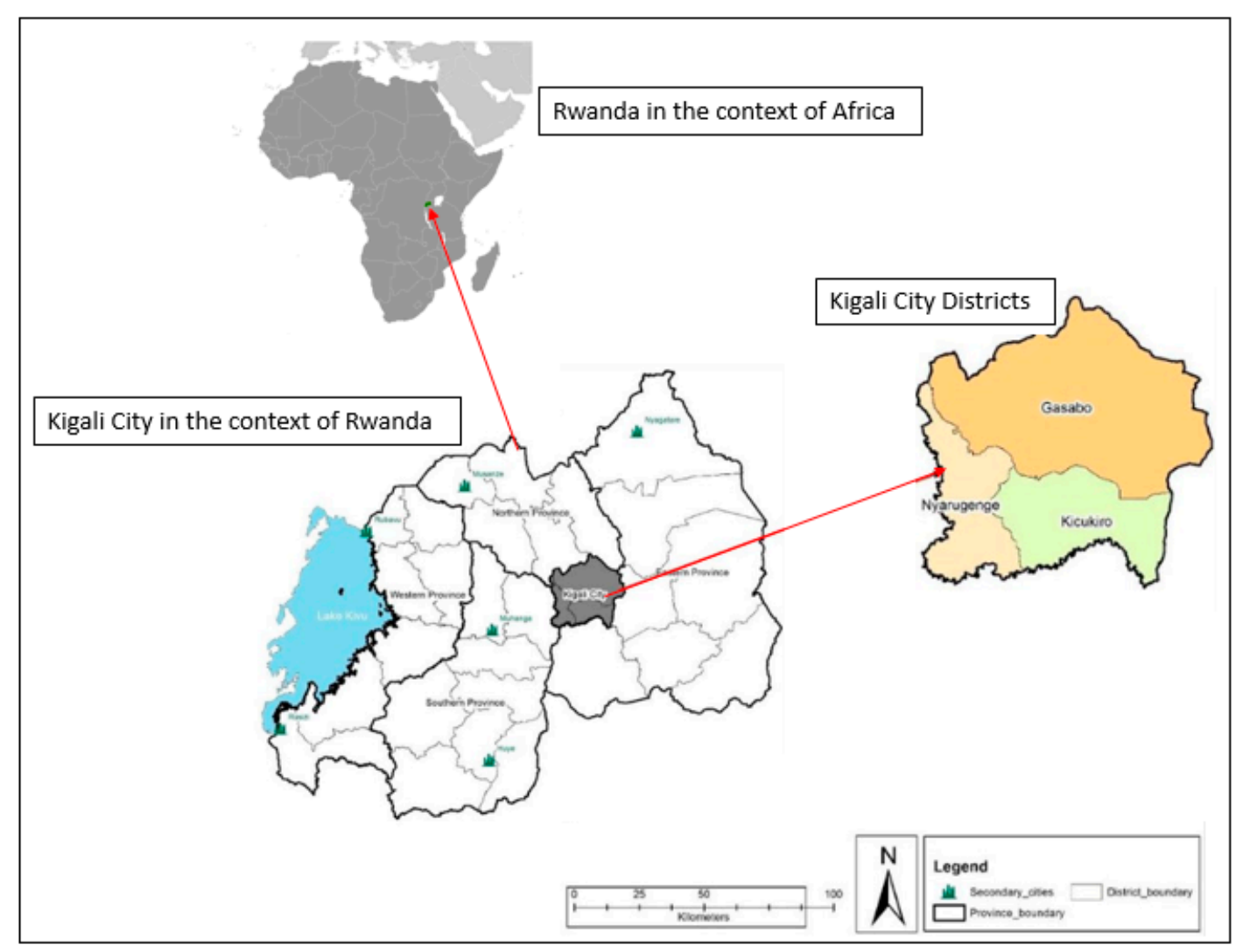

Figure 1. Administrative map of City of Kigali. Source: Modified from [37]. 
Kigali has experienced an unprecedented population growth (rate of $4 \%$ per year) over the past two decades. From a population of nearly 1.133 million in 2012, it is estimated that this number will increase to 4 million by 2040 [38]. To help accommodate the growing population, in 1991, 2002 and 2005, the city administration expanded the city's boundaries to include rural and agricultural zones where there was no urban infrastructure and services [39]. Population growth has strikingly impacted on spatial expansion but has been inconsistent with the provision of basic social amenities. The net result has been uncontrolled growth of informal settlements and environmental degradation [36]. Informal settlements house $79 \%$ of the urban dwellers and occupy $66 \%$ of the built-up area [38]. The city continues to struggle to provide affordable housing units to accommodate the increasing numbers of urbanites. It is estimated that 43,436 affordable housing units will be needed in the next seven years to address the housing deficit [40]. Recent attempts to address informality in the city include adoption of a series of urban policies and legal frameworks aimed at streamlining urban development, with particular emphasis on spatial planning, land redistribution and transformation [18]. These are to serve as instruments to steer the ambitious urban transformation agenda, particularly regularising housing units in the capital city.

Urbanisation in Kigali predominantly followed a concentric urban land use model, from the Central Business District (CBD) to low- and middle-class residential areas, to modern, high-class housing in the suburbs [41]. The city first enacted its urban plan in 1964. However, rapid expansion of the city necessitated the formulation of a new plan in 1982, which underwent elaboration in 2001. The Kigali Conceptual Master Plan, projected up to 2040, was first introduced in 2007. Essentially, the plan was designed to contain the informal urban expansion that has characterised the city since independence [41]. A core observation is that prior to independence, the concentration of city authorities was on the production of plans, with no or little attention to actual implementation. Meanwhile, post-independence saw the city growing rapidly in a spontaneous, uncontrolled and haphazard manner. As a consequence, urban expansion has now extended to wetland areas and onto steep slopes, areas hitherto considered to be unsuitable for human habitation. Interestingly, it is estimated that approximately $19 \%$ of Kigali's built environment is on lands that are unconducive for development [41]. The current urban mosaic of Kigali is characterised by modern businesses, luxury dwellings and neighbourhoods, which co-exist with low-income squatter houses and settlements that spontaneously spring out [42].

The urban perimeter of Kigali is defined by its administrative boundaries. Until independence, the city was limited to the urban area. However, it underwent several territorial expansions in line with the different city plans and administrative reforms that were realised in order to standardise the administration of urbanising areas and to limit informal settlement [17]. In 1975, for example, the Commune Urbaine de Nyarugenge was created after a spontaneous expansion of Kigali's borders in post-colonial times. In 1990, the Commune Urbaine de Nyarugenge was replaced by the Préfecture de la Ville de Kigali (PVK), created to ensure an efficient way of organising the capital city (République du Rwanda law $n^{\circ}$ 53/90). In 2000, in line with the decentralisation ambitions of the authorities and to deal with the spread of population over the hills around the original $112 \mathrm{~km}^{2}$ of what constituted the Préfecture de la Ville de Kigali, its boundaries were redefined, and its administrative entities restructured. The Préfecture de la Ville de Kigali became the Mairie de la Ville de Kigali, on a territory of $314 \mathrm{~km}^{2}$ (République du Rwanda law $\mathrm{n}^{\circ}$ 47/2000). The recent administrative reform of 2005 gave the city its current entities. City of Kigali actually covers a zone of $730 \mathrm{~km}^{2}$, including additional urban and rural zones in comparison to the pre-2005 situation (Republic of Rwanda Organic law $n^{\circ} 29 / 2005$ ). Since there exists a strong relationship between neighbourhood boundaries and urban land use, the next subsection presents the current urban land use in Kigali city.

\subsubsection{Land Use in Kigali City}

Land use in Kigali is officially grouped into two-urban and rural usages. Urban land use comprises $12.1 \%\left(88.40 \mathrm{~km}^{2}\right)$ of the total land area, while the remaining $87.9 \%\left(642.60 \mathrm{~km}^{2}\right)$ is predominantly 
rural [41]. The built-up area is comprised of mixed land use types, including commercial, industrial, infrastructure and residential areas. Figure 2 shows the current and proposed various land use types. Agriculture lands occupy the biggest portion of the land area, followed by the wetlands and forests.

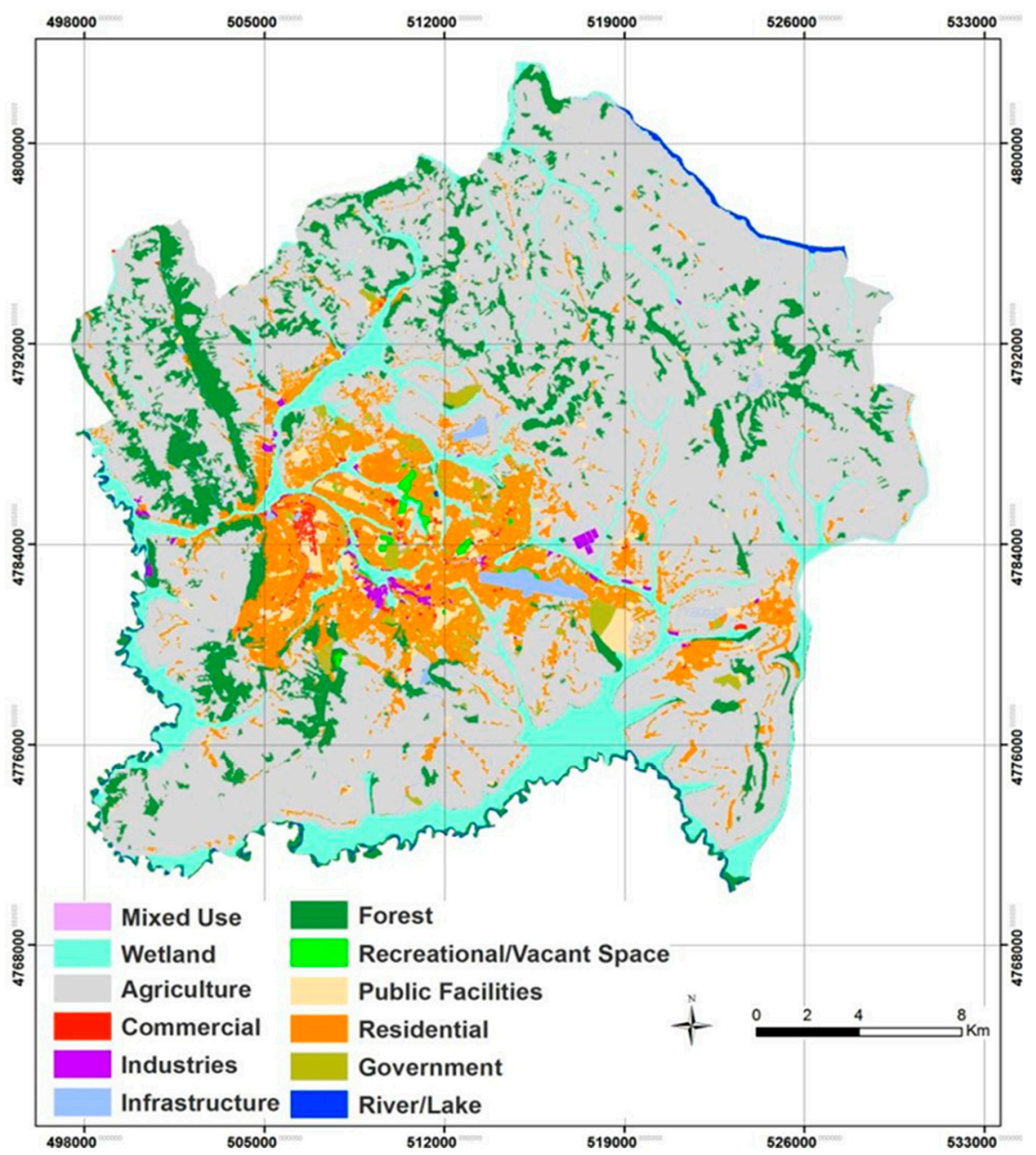

Figure 2. The land use types in Kigali city. Source: [41].

\subsubsection{Urban Development Policies in Rwanda}

Rapid urbanisation and concomitant challenges have given strong impetus for modern day urban development strategies. With cities generating more than $80 \%$ of global GDP, a controlled urbanisation has every potential to make significant contribution to sustainable development, particularly by spearheading innovation and increased productivity [5]. National urban development policies have become major tools not only to control urbanisation and its social costs, but also to foster competitiveness, innovation and social inclusion [43].

The post-genocide era in Rwanda has witnessed a concerted effort by the national government to streamline spatial development, pioneering from her capital City, Kigali. Policies of varied shapes and sizes have been promulgated over the past two decades to catalyse both quantitative and qualitative development. Urban development, however, continues to be a major policy object. Figure 3 shows the various post-genocide policies that have characterised and continue to serve as a framework for urban development in Rwanda. 


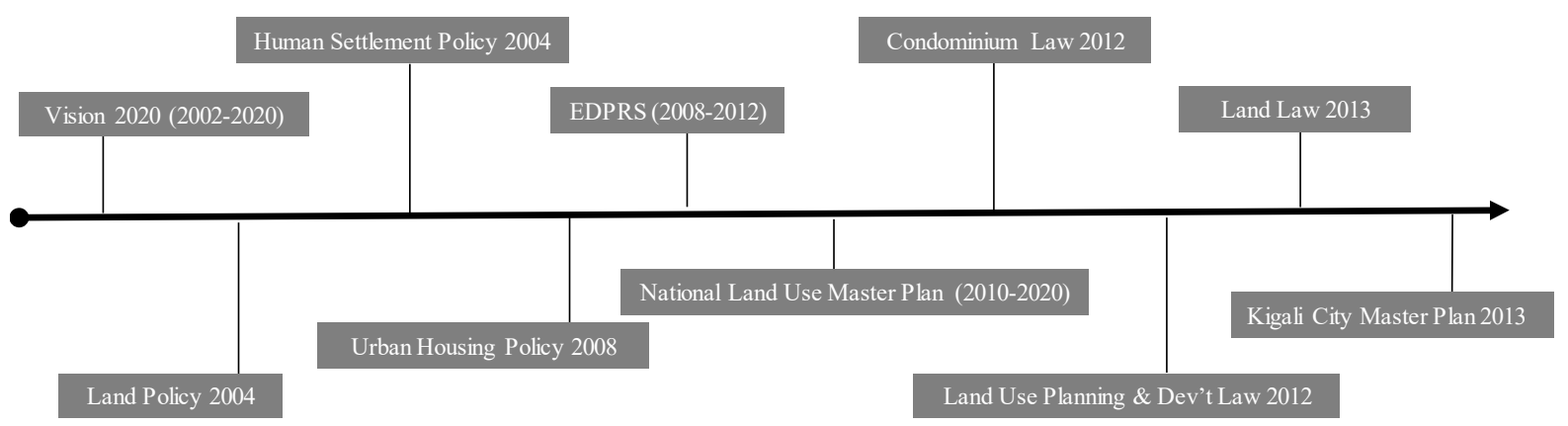

Figure 3. Temporal scale of urban development policies in Kigali. Source: Authors based on Rwanda's urban development policies.

On the policy outlook, the overarching vision 2020 document spelt out main developments, policies and regulations that needed to be elaborated and implemented in all developmental domains from 2002 up to 2020 [44]. Other urban development-oriented policies have been formulated to complement this vision and prepare Rwanda for a sustainable future through various perspectives. The human settlement policy seeks to improve settlement conditions of urban dwellers by providing context-specific strategies to curb the spread of informal settlements [45]. A related policy is the urban housing policy, which uses spatial planning systems to control urban development and spatial expansion of cities [46]. In particular, the Economic Development and Poverty Reduction Strategy (EDPRS) and the Land Policy, have nationwide coverage. On the one hand, the EDPRS aims to improve the living conditions of the poor, in addition to developing economic infrastructure, enhancing good governance and promoting private sector development [47]. The Land Policy, on the other hand, ensures proper usage and management of national land resources [48]. Of particular importance, however, is the 2013 Kigali Master Plan seen here as the final product of a long-term committed planning process. It contains detailed proposed land use and zoning plans that will serve as a guide for the city's future urban development agenda. It especially provides zoning maps for future growth in 2025 and 2040 [41]. It dictates how the Commercial Business District (CBD), industrial areas and residential areas have to be developed, following strict spatial planning regulations. With the exception of the 2013 master plan, it is not clear how effective the other policies have been, as there is limited evidence to measure their impact. The Kigali city master plan is widely heralded as being responsible for the current city transformation.

\subsection{Methodology}

This section presents the study approach and the underlying theoretical assumptions, alluding to the various research methodology paradigms before detailing the research methods employed within this study.

\subsubsection{Study Approach}

In every scientific enquiry, the choice of a method is predicated on the aims and objectives of the research work. For the methods to be more articulate, sampling of expert interviewees was carefully done. To investigate how practitioners have operationalised the concept of neighbourhood, a qualitative approach was considered to be most appropriate. In addition to studying subjects in their natural setting, qualitative research seeks to make sense of, or interpret things, in terms of their meaning to people [49]. In this perspective, realities of neighbourhoods in Kigali was seen in the lens of participants as a shifting narrative in which the subjectivity was viewed as important. Given the subjective nature of the understudying phenomenon, this approach offers the opportunity to study everyday behaviour and enables the exploration of and the understanding of the meaning that individuals or groups assign to a social or human problem [50]. Most importantly, it facilitates the understanding that people ascribe to their environment [51], and in the present case, the concept of 
neighbourhood. More relevantly, the qualitative analysis predominantly deals with the composition of peoples' meanings, descriptions and values of their neighbourhoods towards an outcome that seeks to develop explanatory concepts and models of boundaries and typologies of neighbourhoods in Kigali.

Quantitative research differs markedly from qualitative research. Quantitative research, seen to be static and measurable, is more suitable for analysing linearity in 'cause and effect' questions, and objectively in testing objective theories by examining the relationship between different variables. The latter approach was deemed unsuitable for the present study, as it would not allow practitioners perceptions and feelings to be explored in detail. Therefore, this study utilised the qualitative approach, given the subjective nature of the issue under investigation. The present study draws from available scientific literature, national planning documents and 25 interviews with policy makers (city officials and councillors), urban planners (property developers, architects and consultants) academics and residents (community leaders). In the following section, the various data collection methods employed in this study are explained.

\subsubsection{Data Collection}

\section{Expert Interviews}

In this study, twenty-five participants were recruited on the basis of their practice and residential experiences. This included five major groups: policy makers, urban planners, academics, architects and residents. Table 1 shows the breakdown. This study interviewed different practitioners and residents to provide diversity, making it possible to identify similarities and differences in their conceptualisation of neighbourhood. The groups had a mixture of genders (16 male and 9 female practitioners) and ages (average age was 38). Purposive and snowball sampling techniques were used in the recruitment of the participants. This was necessary because of the specialised nature of the topic. Initially, known acquaintances were contacted through emails to take part in this study. Out of the fifty emails sent out, only seven replied. The low response rate led to the employment of snowball technique, where each practitioner was asked to suggest a suitable colleague or partner within his or her professional circles to be invited to take part in this study. This approach proved effective. This study interviewed only those fluent in English and Kinyarwanda (the Rwandan national language). The interviews sought to explore three major issues (see Appendix A for interview questions to the participants): (1) understanding of neighbourhood as a spatial unit, (2) neighbourhood typologies in Kigali and (3) how neighbourhood boundaries are defined in practice.

Table 1. A breakdown of study participants.

\begin{tabular}{cc}
\hline Participants Type & Number Interviewed \\
\hline Policy makers & 6 \\
Urban planners & 6 \\
Academics & 7 \\
Residents & 6 \\
\hline Total & $\mathbf{2 5}$ \\
\hline
\end{tabular}

\section{Field-Based Observations and Notes}

Additional data was collected through field observations of the urban environment at Kigali. This way, the research significantly embraced the importance of field notes in enhancing data and providing rich contextual information as has been found pragmatic in the research landscape [52,53]. The field notes and photographs provided the needed contextual information, which allowed the research to be framed within a certain time and place [54]. Observations focused on how people were using certain areas within the city, the buildings and how they were situated within various neighbourhood space, as well as the overall morphology of the city. Field observations specific to this research were conducted twice- before and after interviews with practitioners. The first exercise, 
pre-interview fieldwork was carried out in February 2019. The exercise, which lasted four days, was geared toward familiarising ourselves with urban and spatial development in Kigali with respect to neighbourhoods. The researchers observed various areas, including Kigali Central Business District (CBD), high, middle and low-income communities. The post-interview field observations aimed to validate the neighbourhood typologies. Based on the information provided by the practitioners, the team visited each neighbourhood type to understand their morphology and characteristics, in addition to taking pictures of each. The second field exercise, post-interview fieldwork was carried out in September 2019 and lasted three days. The field observations and notes served to complement those of the interview data.

\subsubsection{Data Analysis}

Thematic Analysis (TA) Approach

In presenting the results, this study employed the Thematic Analysis (TA) approach. TA is a method of identifying, analysing, and reporting patterns (themes) within data [55]. TA is particularly important as it offers the opportunity for open-ended responses from interviews to be explored at a deeper depth which quantitative analysis is unable to do [55]. The approach is widely used in different fields, including but not limited to education, sociology, anthropology and health sciences [56-58]. In general, robust qualitative analysis involves five steps (6) (see Figure 4), which form the basis for the present analysis. Compiling, which is transcribing the data into a useable form, is the first step in presenting qualitative data. This helps to find meaningful answers to research questions [58]. Disassembling the data means taking the data apart and creating meaningful groupings, which can be done by coding or on the basis of predetermined themes-the case in the present study. In reassembling, themes are put into context, followed by interpretation and conclusion. The data compilation, disassembling and reassembling were carried out using the matrices technique [58] in Microsoft Excel. This study followed the five established steps in reporting the results.

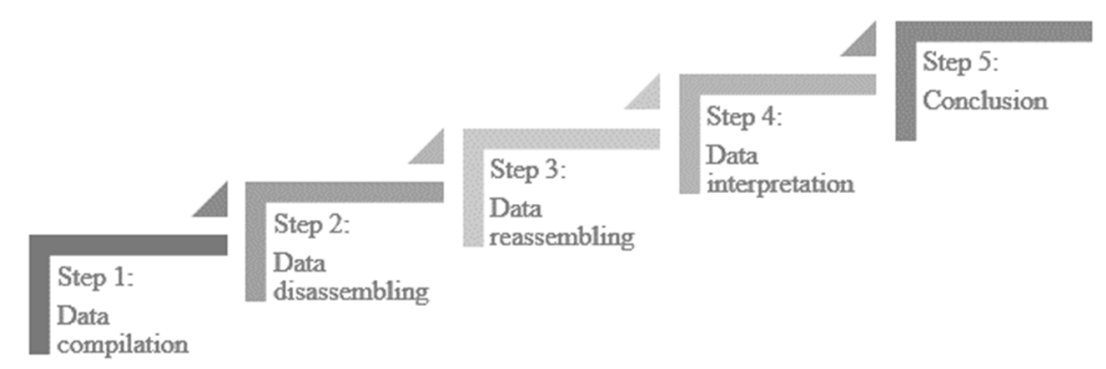

Figure 4. Data analysis procedure employed in reporting the qualitative results. Source: Based on the work of [59].

\section{Results}

In this part, this study presents how neighbourhoods in Kigali have been conceptualised and defined, with respect to boundaries and typologies. The first part documents voices from the field, whereas the second part discusses comprehensive observations of neighbourhoods in Kigali city.

\subsection{The Perception of a Neighbourhood by Study Participants}

\subsubsection{Conceptualising Neighbourhoods in Kigali City}

Although neighbourhoods are known by various terminologies and meanings, there appears to be some consensus among the interviewed participants. According to the participants, the conceptualisation of neighbourhoods in Kigali was largely shaped by factors as grouped into the following categories: morphology (settlement history and structure), lifestyle and living conditions 
of the residents, accessibility to infrastructure and services, administration and social cultural considerations. Figure 5 shows the quantified responses to neighbourhood conceptualisation.

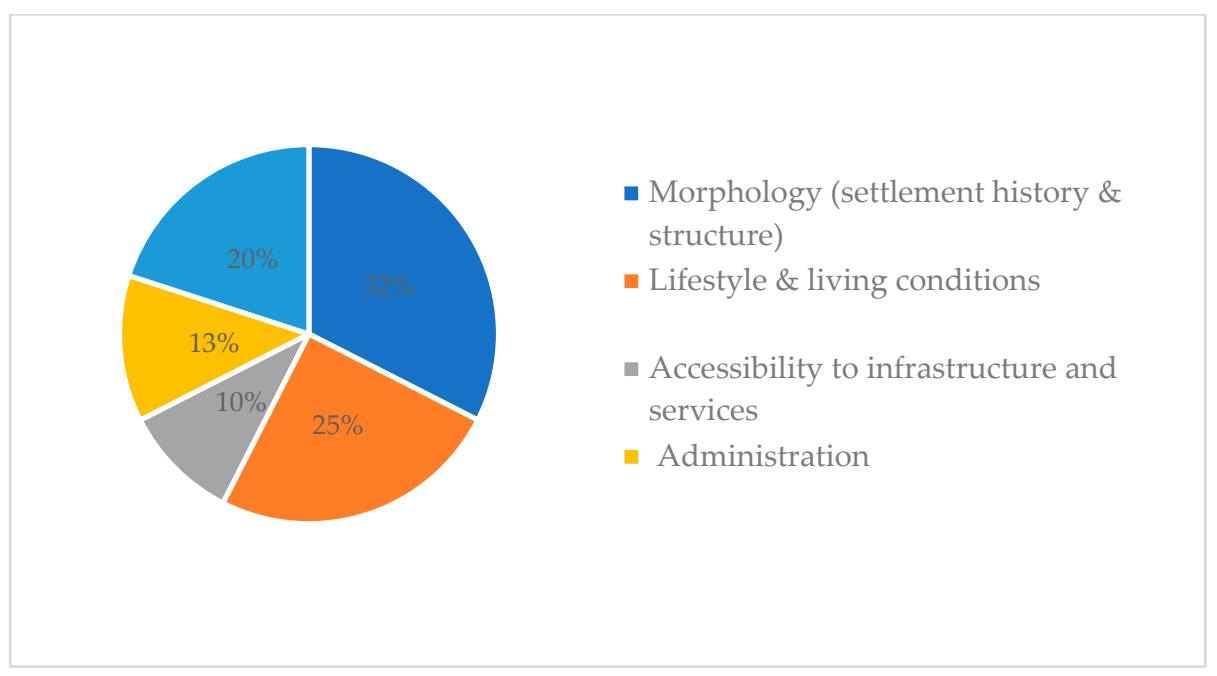

Figure 5. Conceptualisation of neighbourhood in Kigali. Source: Authors.

As illustrated in Figure 5, 32\% of the respondents conceptualised a neighbourhood based on morphology while $25 \%$ agreed that lifestyles and living conditions determine the conceptualisation of neighbourhoods, with $20 \%$ favouring the social cultural considerations. This resonates with the theoretical underpinning that every resident should be able to live in a socially, economically and environmentally healthy neighbourhood.

Evidently, Kigali has emerged strongly as a modern city in Africa over the past two decades. In recent times, however, urban development practitioners and policy makers have come to the realisation that the relevance of the concept of neighbourhood in practice cannot be ignored. To prove this need, participants provided interesting insights, alluding to a gap in the way neighbourhoods are defined and understood. During the interviews, some respondents considered a neighbourhood as a cohesive unit and a tool to ensure that resources (infrastructure, schools, etc.) are properly allocated in order to ensure sustainability in the social well-being of an urban household. The various conceptualisations encapsulate issues such as cluster of common activities over a fair radius within which a level of independence is exercised over certain services. In this perspective, a neighbourhood qualifies as a space unit of people sharing the same characteristics or same history and government established areas with close proximity to social services.

The interviews also revealed that people prefer to settle in a particular neighbourhood because of different factors, including the availability of basic social infrastructures (e.g., schools, health centres, water and electricity), the affordability of the land, construction material type and global view of the site as per the Kigali master plan requirements. Also important is the ease of access to the building permit as well as social cohesion. In particular, the majority of the study participants alluded to multiplicity of factors, including social processes beyond the spatial boundaries, as being critical to defining neighbourhood in practice.

\subsubsection{Defining Neighbourhood Boundaries in Kigali: Perceived and Physical Boundaries}

Boundaries are important in understanding neighbourhoods. According to the study participants, boundaries can be either perceived or actual physical elements. In synthesising the various opinions, four factors emerged as being critical for defining neighbourhood boundaries. The factors include: structure/built forms, social fabric (characteristic of residents)/no boundaries, administrative boundaries and geographical features (topography). Figure 6 shows the quantified responses. 


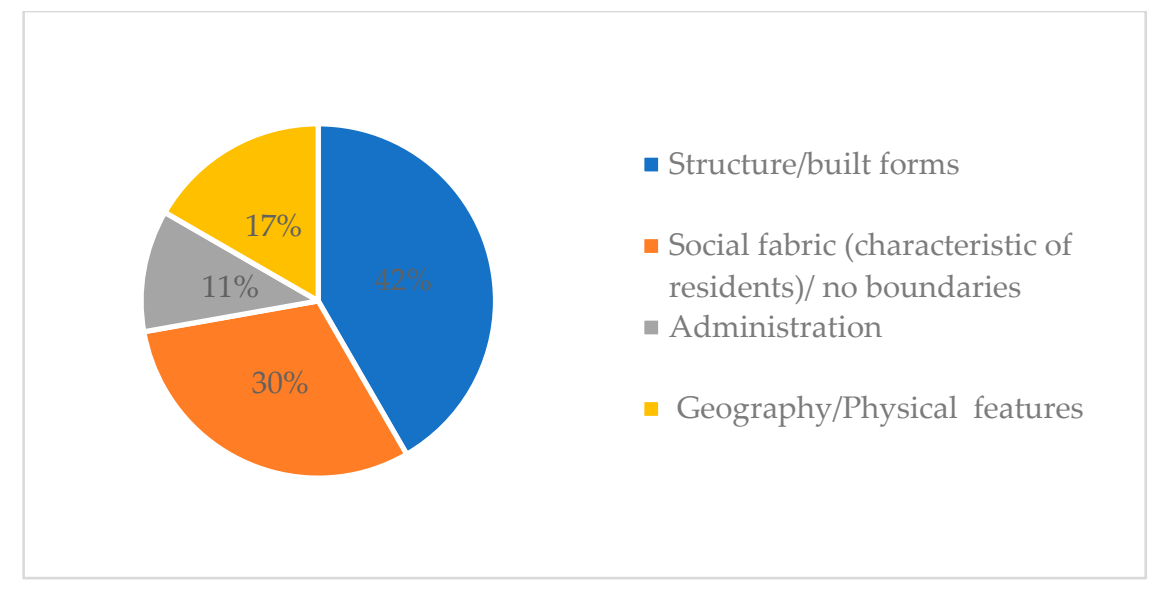

Figure 6. Factors shaping neighbourhood boundaries in Kigali. Source: Authors.

As illustrated in Figure 5, 42\% of the participants reported that neighbourhood boundaries are shaped by the urban structure or built forms. A considerable $30 \%$ believed that neighbourhood boundaries are informed by the social fabric. In that perspective, neighbourhoods can be without physical boundaries, which is more common with informal settlements in developing countries. The proportionate rates for administration and geography being the lowest in this theme, suggest that these factors are less associated with peoples' understanding of neighbourhoods in Kigali. From the participants' perceptions, boundaries can be either "hard" like infrastructure and/or topography, or "soft" like administrative boundaries (districts, sectors and cells) and/or the reputation of a certain area.

Importantly, without tangible boundaries, urban planning would be very challenging. Since traditional neighbourhoods have evolved and merged over time, planning needs to be understood as a process that evolves and therefore to ensure workable regulations and implementation strategies, continuous fieldwork and mapping are critical.

\subsubsection{Neighbourhood Typologies in Kigali}

In terms of neighbourhood typologies, there was general agreement among the participants that neighbourhoods in Kigali can be categorised based on function, location, residents' socioeconomic and cultural characteristics, urban fabric and accessibility to infrastructure and services. Figure 7 shows the quantified responses.

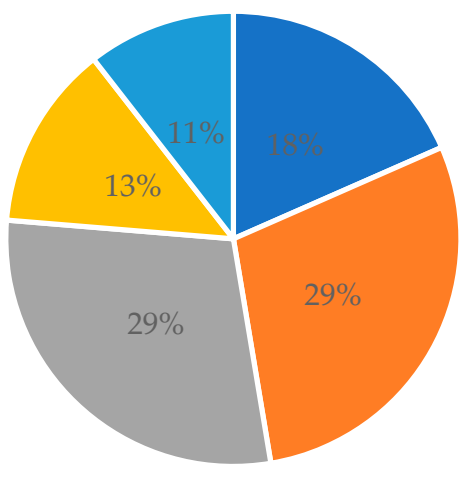

- Function

- Resident characteristics (socioeconomic, cultural)

- Urban fabric/structure

- Infrastructure and services

- Location

Figure 7. Factors determining Kigali neighbourhood typologies. Source: Authors. 
From Figure 7, residents' characteristics and urban structure were ranked the top two factors in the determination of neighbourhood typologies. Since typologies are also largely perceived, it means that residents' socioeconomic and cultural characteristics can have a huge impact on neighbourhood typologies. Only $18 \%$ agreed that the functions in a neighbourhood influence the perception of neighbourhood typologies. Contrary to theoretical underpinnings, location and infrastructure and services accessibility scored the lowest, $11 \%$ and $13 \%$, respectively.

According to the interviews, in terms of function, a neighbourhood could be commercial, administrative, industrial, residential, transport based, religion based, school based, or recreation based. In terms of residential use, a neighbourhood could be a high, medium or low standard residential area or a slum. For location, it could be central (downtown), peri-central or suburb, and with respect to age, neighbourhood could be old, new or modern neighbourhood. In extending this view, some participants' views portrayed an interesting complexity that there is not always one straightforward criterion for determining neighbourhood typologies. It was, however, clear that topography and structure indeed play a big role in the formation and transformation of neighbourhoods in Kigali. Meanwhile, there has been growth in a number of neighbourhoods whose morphology comply with the urban Masterplans.

In general, neighbourhood typologies speak to a mixture of dimensions, including housing and urban planning settings, geographical features and social processes. The next section presents results from an in-depth observation of the neighbourhood typologies in Kigali city.

\subsection{Comprehensive Observations of Neighbourhood Typologies in Kigali City}

As reflected in the views of the research participants, in practice, this study finds that although neighbourhoods in Kigali are still not boldly defined in the city Master plans, attempts were made to categorise them into the three conventional typologies: planned, unplanned or informal and a mixture of the two-mixed neighbourhoods. Below, the characteristics of each category are highlighted.

\subsubsection{Planned Neighbourhood}

Planned neighbourhoods are characterised by clearly separated and demarcated plots and organised road networks. They are largely characterised by low density or single-family homes built in a uniform way that optimises the land. This type of settlements occupied 11.5 per cent of Kigali's built area in 2012 [38]. Planned neighbourhoods are equipped with basic infrastructure, such as accessible tarmac or stone-paved roads, with buildings constructed with bricks or cement blocks and with roofing of industrial tiles or metal sheets. Particularly, buildings are constructed according to a set standard, with the majority of households coming from the high-income economic class. Middle-class households are few in number. Population density is approximately 2000 to 5000 people per $\mathrm{km}^{2}$. Planned neighbourhoods are divided into three subcategories: high, medium and low standing.

The 'high standing' neighbourhood comprises luxurious single-story houses (e.g., Estate 2020, Gacuriro Nyarutarama, and Kigarama) and private estates (e.g., Vision City, Umucyo Estate and Hillside estate, Kabuga). These estates have the same commonality of being built by private developers and located at various hill slopes away from the city centre. Field observations in Vision City afforded the opportunity to observe estates with detached, semi-detached villas and luxury apartments with all modern amenities but seemingly more expensive in sale price that they cannot be affordable for most local residents. In Kigarama sector, for instance, a small-scale type of estate was visited, where the developer adopted the 'shell and go' strategy. He bought the land and built 18 well-designed two-storey houses, emphasising on an aesthetic quality of external finishes, perch with pillars, but left the internal design and furbishing to the purchasers. Obviously, this is a slightly cheaper option of living compared to the Vision City, but residents highlighted that it was still not affordable to the majority of Kigali City dwellers. Figure 8 is an example of planned neighbourhood. 


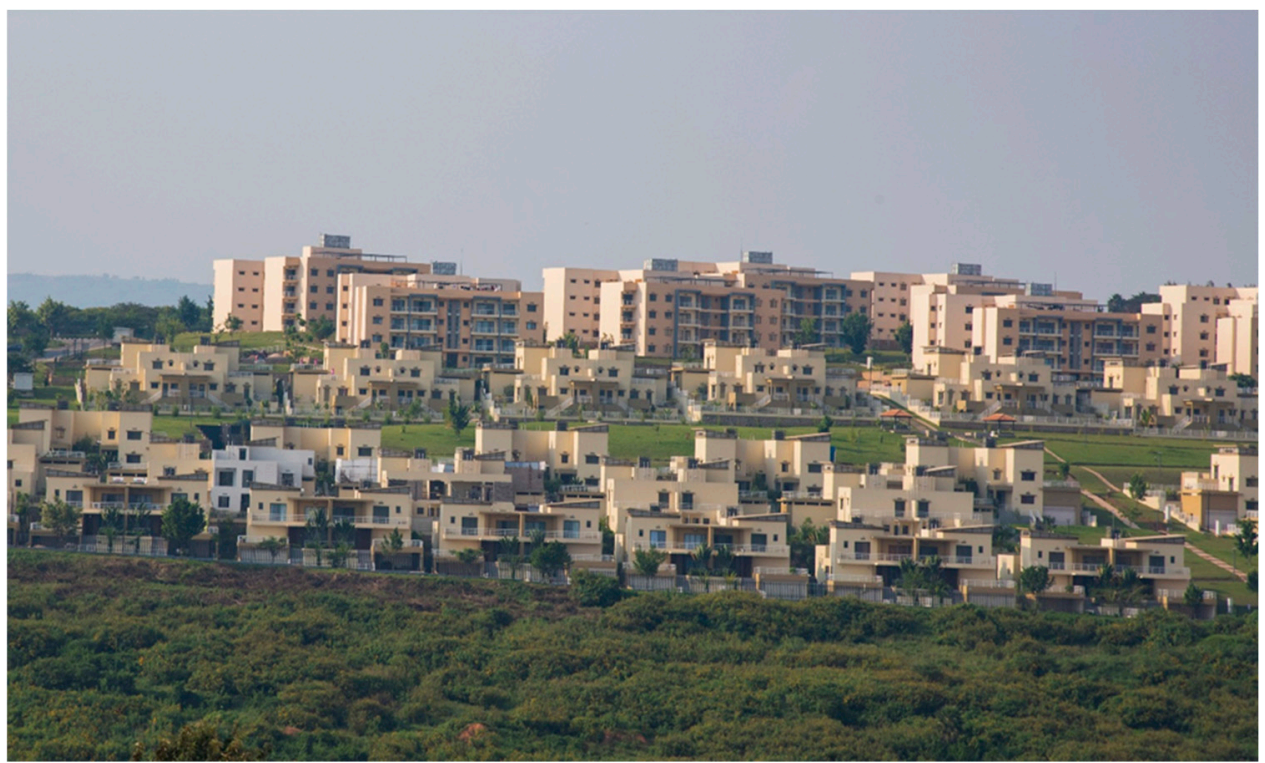

Figure 8. First category planned gated neighbourhood: Gacuriro Vision City. (Source: authors).

The second category is the 'medium standing' neighbourhoods composed of villas built with high-quality materials but without multiple floors, as it is the case in Kimironko, Niboye, and Kagarama and Kabuga. Figure 9 is an example.

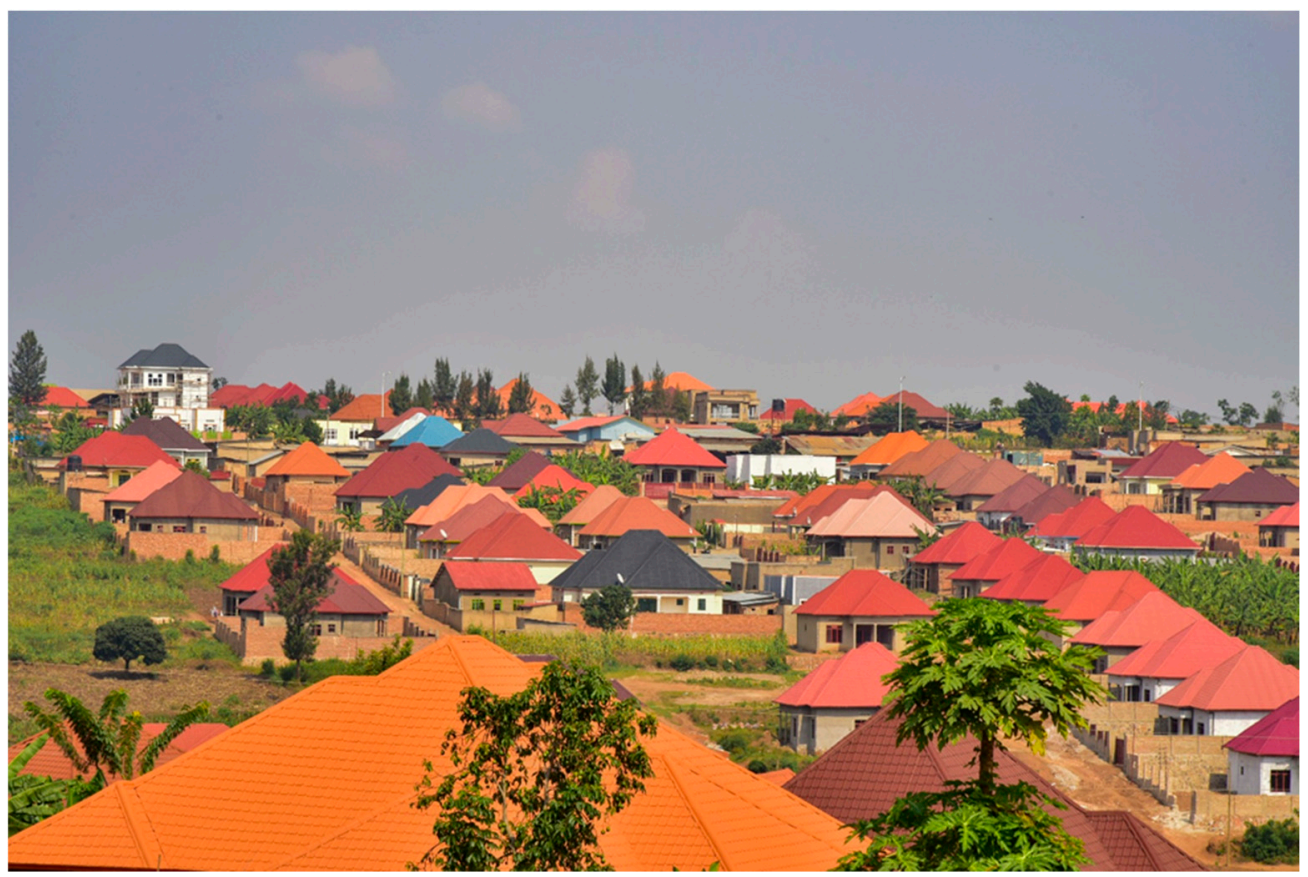

Figure 9. Second category planned neighbourhood: Kabuga (Source: authors).

The third category comprises 'low-standing' neighbourhoods that are constructed on planned sites with access to basic services. Here, buildings are largely constructed with low-grade construction materials. A model exemplar is that of Batsinda social housing project (Figure 10), which was built by the government to resettle families removed from the central informal neighbourhood of lower Kiyovu in Ubumwe cell. The city authorities and UN Habitat consider the Batsinda as a successful model of planned settlement for low-income people. 


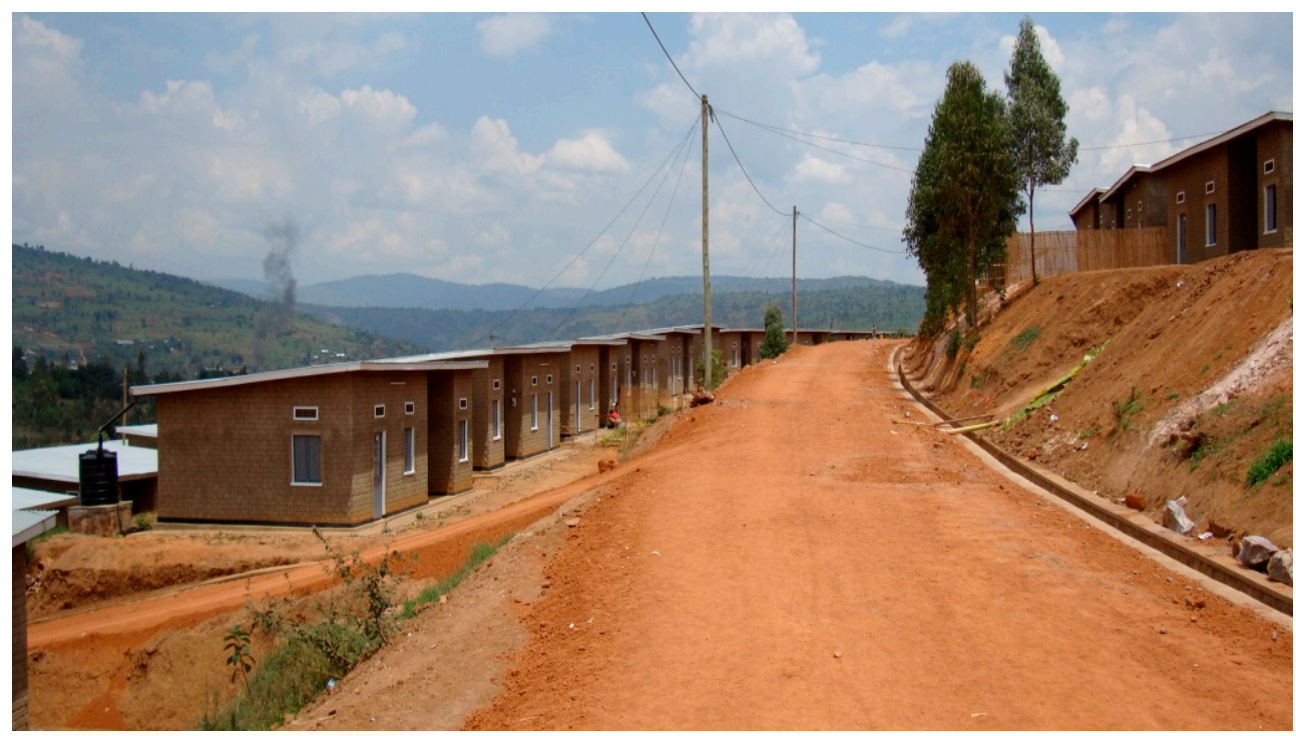

Figure 10. Third category planned neighbourhood: Batsinda (Photo credit: C. Kalisa).

However, planned, road and other infrastructure in Batsinda are below standard. In particular, almost all roads are untarred (see Figure 10). Given that it is a slightly cheaper option of living than buying or building a house, the area has been experiencing increased gentrification in recent times, mainly by the middle class who cannot afford expensive housing options in the city. This is an area that needs further research to ascertain the magnitude. A legitimate question to ask is where do the [poor] displaced households go? Are they going back to the city centre or forming new informal enclaves? The latter seems plausible, casting doubt on the effectiveness of expropriation without adequate provisioning in Kigali.

\subsubsection{Unplanned/Informal Neighbourhood}

Unplanned, or as synonymously referred to as informal settlements, are largely characterised by rudimentary construction materials and techniques that are non-durable, located on a hazardous site, bearing an area below the minimum legal house area or plot size and/or lacking adequate infrastructure and services. Informal settlement in Kigali is considered illegal, because they do not comply with urban planning requirements (construction with official permit), though residents may hold legal land titles. Interviews revealed that the growth of such enclaves in Kigali is attributed to the late urbanisation as well as the low household incomes coupled with high costs of living. Other reasons include poor housing financing system, the high cost of building materials and poor enforcement of existing housing laws [39]. Such settlements can be categorised as: unplanned slum areas with limited access to facilities and poor living conditions; unplanned low-rise residential urban housing around the city centre lacking services; and unplanned residential areas in rural farmlands on the city's periphery [60]. They can be classified as 'spontaneous neighbourhoods' which, according to [61], are full of small individual houses made with bricks (often of the adobe type) or with breezeblocks but without any modern comfort and equipment. Roads are generally unpaved and mostly only accessible for pedestrians, with occupants mainly coming from low-income class (daily wageworkers or informal traders) and new rural immigrants. In particular, such areas are characterised by a strong scarcity of land with concentrated houses lacking an appropriate development plan. Field observations revealed that land ownership is in the hands of private individuals. Interestingly, property owners could have several houses together; they may decide to live in one house and rent the rests to other people. Field visits further revealed that some of these neighbourhoods have been created in peripheral zones to the city official boundary (due to land affordability and attempt to escape strict urban construction regulations), but have been integrated into the administrative boundaries of the city throughout time. 
Population density in informal neighbourhoods is over 10,000 inhabitants per $\mathrm{km}^{2}$ (e.g., Kibiraro, Nyagatovu, Gatsata, Cyahafi and Nyabisindu). Figure 11 is an example of informal neighbourhood in Kigali.

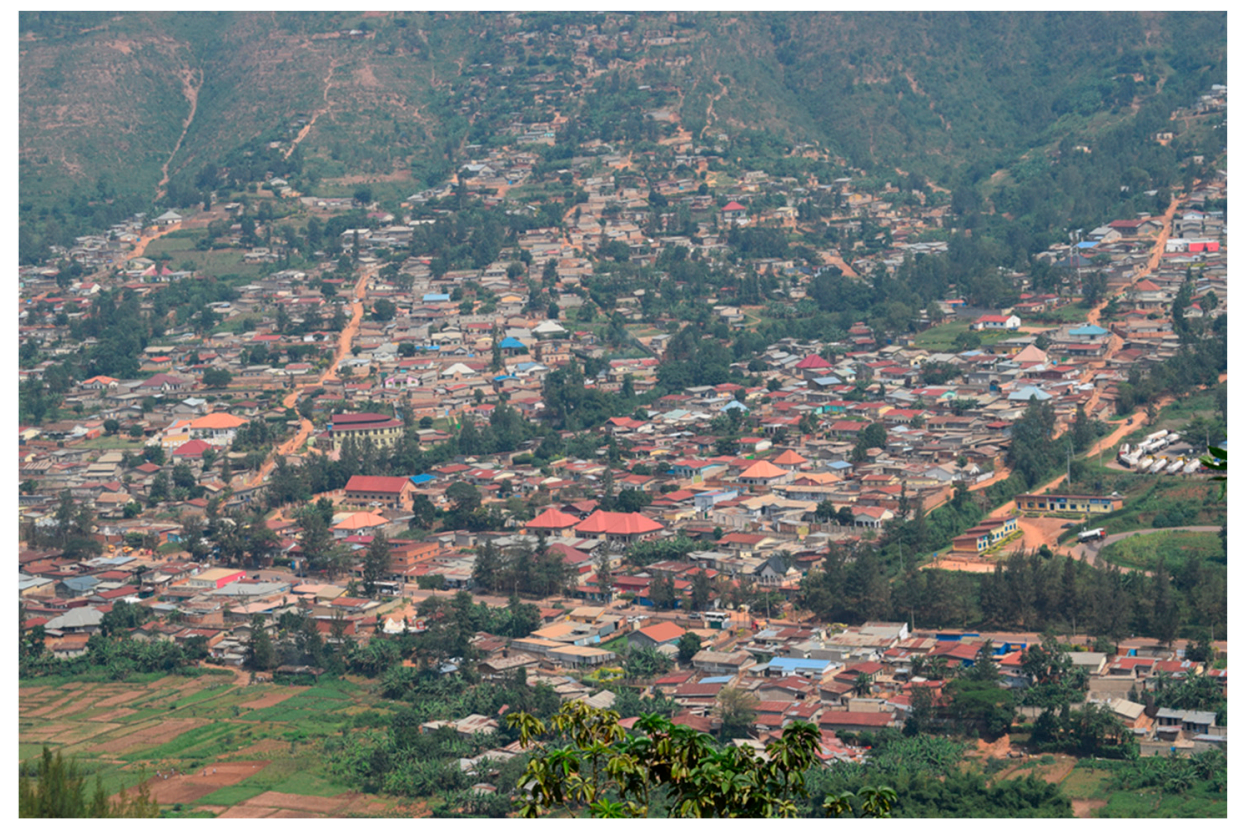

Figure 11. Informal neighbourhood: Gatsata (Source: authors).

For a rapidly urbanising city like Kigali, unplanned/informal settlements are not without consequences. [36] highlights that due to the rapid pace of urban growth, transportation, housing, education, health, sewerage and sanitation infrastructure and other municipal services have been unable to keep pace with the speed of development. As a result, sewage and wastewater from informal settlements often flow in open drains and can seep into groundwater and run into wetlands [62]. Regardless, given that the majority of migrants are poor and mainly migrate in search of better economic opportunities, their first point of call in the city is the informal settlements, where many are able to rent (and house share) and later construct their own informal units-largely replicating housing patterns in rural areas, thereby perpetuating informality.

\subsubsection{Mixed Neighbourhood}

Observations revealed that mixed neighbourhoods are a mixture of planned and informal settlement areas that have progressively merged around a planned site (e.g., Zindiro, Masizi) or neighbourhoods that resulted from urban transformations, either upgrading or degradation, that affect the initial structure of a planned or an unplanned neighbourhood. Biryogo is an example of an old planned neighbourhood established since 1960s as a residential area for public servants that has gradually degraded due to its intensive densification.

The upgrading is done from the initiative of the residents themselves or by the Government intervention. On the one hand, the initiative of the residents takes place in informal neighbourhoods that have mostly developed in periurban zones and transferred to the city circumscription throughout its spatial expansion (e.g., Kabeza). The upgrading is characterised by paved roads, newly built or renovated houses, provision of water and electricity facilities. Plots are bought by new owners who replace the old buildings with houses that are consistent with the city construction code.

On the other hand, upgrading through the Government intervention consists of efforts to promote equitable social development and environmental integrity in cities of Rwanda. A typical example is Agatare neighbourhood of Nyarugenge district. The Agatare Upgrading Programme aims to transform informal neighbourhoods into better residential areas. This is significant, as it illustrates how one 
neighbourhood can transition to another, evidently supporting the neighbourhood transition thesis. The case provides another, yet very different approach of housing to that the government took in 2008 - the relocation of residents from Ubumwe informal settlements to Batsinda formal housing. Clearly, upscaling such projects and specifically targeting poor households and neighbourhoods would go a long way to reduce the current affordable housing deficit while building sustainable cities and neighbourhoods. The upgrading process focuses on opening new wider roads along with provision of basic drainage, improvement in electricity and water supply. Interaction with residents during field visit revealed that though few households were expropriated to pave the way for the construction of new roads and other basic infrastructure, the project, overall, has substantially improved accessibility and general security. It was also made known that residents are now authorised to build new houses or upgrade their old units, which hitherto were earmarked for demolition. Figure 12 is an example of mixed neighbourhood in Kigali.

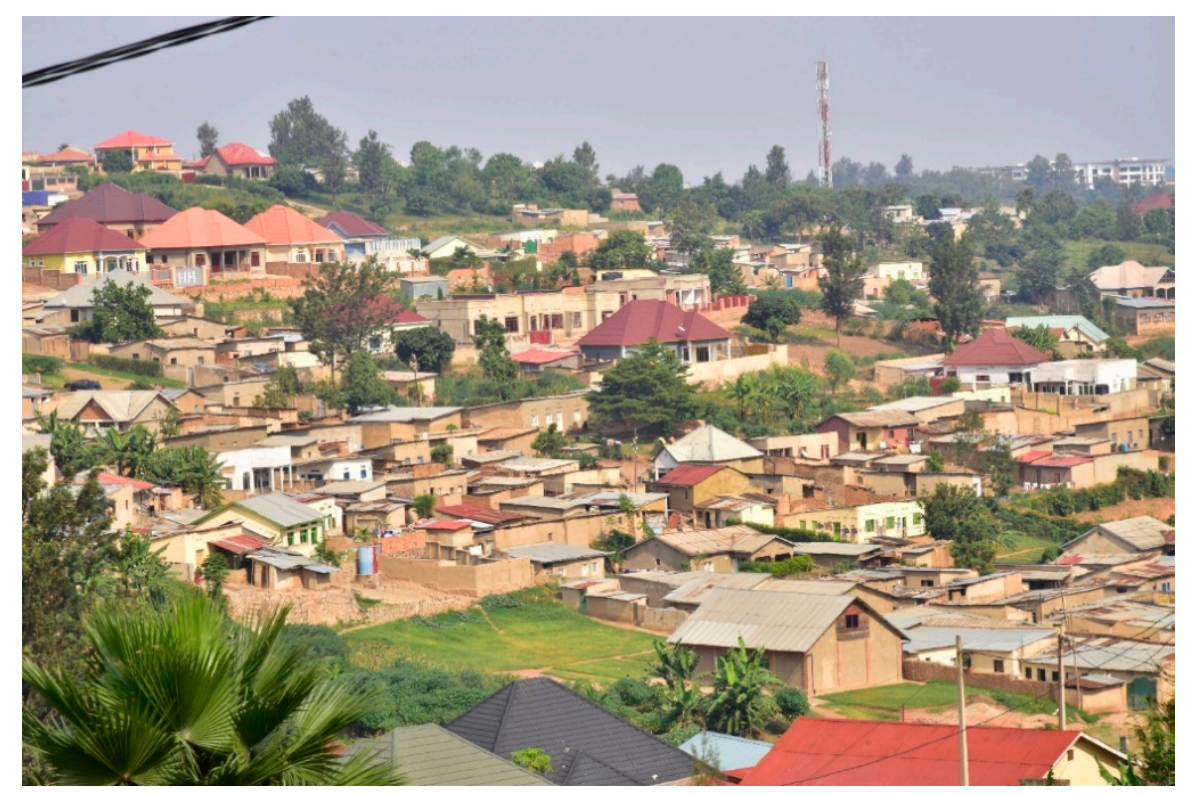

Figure 12. Mixed neighbourhood: Zindiro (source: authors).

\section{Discussion}

\section{Linking Theory to Practice: Placing Kigali Neighbourhoods in Context}

Based on the forgone results, it can be seen that the concept of neighbourhood has followed theoretical application in Kigali. Thus, the practical conceptualisations resonate with theory. This is because elements, such as interconnectedness, space, people and activities, are factors well acknowledged in literature as being critical in defining a neighbourhood. The implication is that practitioners are likely to be guided by theories and literature in their work. This notwithstanding, the typologies are overly one sided-focusing mainly on housing, with no clear distinction on hierarchical components, such as socioeconomic composition and degree of informal network. This study argues that this has the potential of engineering segregation and social exclusion, which are recipe for violence, protest and crime, in addition to perpetuating poverty. This study proposes well-serviced mixed neighbourhood types, which will foster a strong sense of belongingness while strengthening and reshaping the social fabric, thereby mending the strained social capital that characterizes [affluent] urban neighbourhoods in contemporary times. From the narratives, however, it can further be argued that the boundaries invoke both physical and subjective constructs. The physical model thesis can be applied to the formal neighbourhoods in Kigali. Given their well-planned nature, planned neighbourhoods (e.g., Estate 2020, Gacuriro,) fit into the physical boundary model when viewed from the perspective of housing type. Using the housing lens, a neighbourhood can be a good 
exemplar (not always) of identifying and visualising societal inequality at the city level in developing countries. This is especially true as the affluent usually tend to cluster in elite neighbourhoods. The sharp spatial contrast presented by housing types in cities do not only cast a dent on national government urban development policies, but also question, to a large extent, spatial planning and housing strategies. The case of Kigali presents a classic example, where city level infrastructural development contradicts neighbourhood conditions, albeit with few exceptions. The situation in Kigali is consistent with that of larger East Africa, where evidence has shown that urban growth is usually not supported by provision of adequate infrastructural development at the local level $[63,64]$. Field observations and interviews with practitioners revealed that there is a conscious effort by government to physically transform the city, with expropriation (in the name of public interest) being the order of the day. Although brilliant in its conceptualisation, the seeming negligence of housing and livelihood opportunities for the urban poor and the marginalised has been heavily criticised. Given that the government is bent on following modernist planning paradigm, there is the need to adjust the current physical development orientation to be in line with the Global Planners Network documentation on "Reinventing Planning", which upholds good principles, including inclusiveness between sectors and stakeholders as well as recognition of the reality of informal settlements and slums [65]. Currently, affordable housing remains a major developmental challenge in Kigali, and a recent paper highlights that "much of the improvements we see in Kigali today are cosmetic and driven by the government's obsession to portray an image of success rather than to lay the foundations of lasting economic growth" [66]. It should be noted that expropriation in public interest (compulsory acquisition of land by the state) was a key requirement for the effective implementation of the 2013 master plan.

Elements of subjective boundary thesis can also be observed in Kigali city, albeit minimal. The informal and mixed neighbourhoods reflect how various social processes, particularly class, create and shape human society. In trying to make sense of their perception of neighbourhoods, the majority of the interviewees referred to a number of social processes. These perceptions seem to erode the notion of a neighbourhood as a spatial unit, allowing the intangible descriptions to convey a strong message of the unique sense of belonging that residents share. Residents feel comfortable and proud of being familiar with each other than of knowing how big or small their neighbourhood is. It is argued that the everyday sociocultural exchanges within the neighbourhood have the potential to co-produce a sustainable neighbourhood. Residents consider any forms of informal social support to be a good neighbourhood practice, which gives them reasons to value living in certain neighbourhoods. It should be noted that residents of these neighbourhoods are largely people of low social class and status. Owing to their spontaneous and unplanned nature, such neighbourhoods tend to be vulnerable to diseases (e.g., diarrhoea and malaria) due to the poor sanitary conditions $[67,68]$. This notwithstanding, their relevance can never be underestimated. It is argued that while such areas form the 'bedroom' and 'transit point' for most middle-class workers due to the high rental charges in the inner city, they also function as destinations' for rural migrants, in addition to serving as a 'laboratory' for testing various social interventions (e.g., health insurance, housing upgrade and re-development projects, among others). Directives such as eviction of offices from residential areas in an attempt to increase occupancy rate in the city's CBD catalyse movement of some residents to the city centre for work. These people return to their neighbourhoods of residence in the evening.

More so, most economic activities are concentrated in and around informal settlements, seen as enclaves, forming the largest market-base for various city goods and services. Clearly, their role in economic development is unquestionable; they are strategically positioned as engines of production, distribution and consumption. In particular, they are areas where innovations are created and nurtured, with the case of Kibera in Kenya $[69,70]$ being an example. In Kigali, however, informal neighbourhoods are undesirable and, hence, continue to face eviction threats due to the desire to modernize the entire city, following the 2013 City Master Plan regulations. Residents in mixed neighbourhoods, as already indicated, have been given the opportunity to restructure their buildings. The city government, with support from the World Bank, is working assiduously to upgrade infrastructure in the shapes of 
paved roads, provision of portable water, drainage systems and sanitary facilities. The Agatare case is considered a success, given that residents continue to report positive impacts on their economic, social and environmental well-being.

\section{Conclusion}

This study aimed to understand the extent to which the concept of neighbourhood has been operationalised in Kigali. It has been shown that the conceptualisation fits into existing theoretical models and knowledge. Neighbourhood boundaries were found to be consistent with both physical and subjective constructs. This study argues that neighbourhoods in Kigali are theoretically and practically driven, reflecting both modernity and originality in terms of the context. On the one hand, and in relation to the modernity paradigm, the planned neighbourhoods with clearly delineated physical boundaries suggest pragmatic attempts by the national government to follow contemporary planning practices. This is supported by the adoption of the Kigali Master Plan (supposedly modelled after Singapore), which seeks to standardize spatial planning, and infrastructural development in the city. It is also further supported by the current urban-related policies, which aim for sustainable cities and communities, as stipulated in goal 11 of the global sustainable development goals (SDGs). This paper unpacks Kigali's context as one that reflects an internal city structure significantly modelled by local policy response. On the other hand, the neighbourhoods represent the local spatial peculiarities, which need context-specific interventions to uplift or transform the current image. Regarding typology, it is largely physical. The physical dominance, it is argued, engineers segregation and social exclusion, which are a recipe for violence, protest and crime, in addition to perpetuating poverty.

Given that the majority of the people in Kigali are living in informal and mixed neighbourhoods, this study further argues that while such areas form the 'bedroom' and 'transit point' for most lowerand middle-class workers, due to the high rental charges in the inner city, they also function as 'destinations' for rural migrants, in addition to serving as 'laboratories' for testing various social interventions. This study questions the current neighbourhood typologies in Kigali as being too loose and physical, reflecting largely housing types and boundaries. The encapsulation is overly silent on salient, yet critical social issues such as livelihood activities, social relations, and ethnicity, which play a major role in defining neighbourhoods. Given the fact that neighbourhoods in developing countries are largely socially produced spaces, ignoring such social variables has every tendency to limit our understanding on their evolution. This study recommends well-serviced mixed neighbourhoods in Kigali. Thus, urban planning must support integrated neighbourhoods in Kigali. With respect to research, future studies are encouraged to build on the current analyses. Studies may explore the application of spatial tools in delineating the various neighbourhood typologies identified in this study.

Author Contributions: Conceptualization, G.B.; methodology, G.B., J.M., V.M.; formal analysis, G.B., J.M., V.M.; investigation, J.M., V.M., G.B., L.M.; resources; SHLC; data curation, J.M., V.M., L.M.; writing-original draft preparation; G.B., writing-review and editing, J.M., V.M., L.M.; visualization, J.M. All authors have read and agreed to the published version of the manuscript.

Funding: This study was conducted as part of the GCRF Centre for Sustainable, Healthy and Learning Cities and Neighbourhoods' (SHLC) activities. SHLC is funded via UK Research and Innovation as part of the UK Government's Global Challenges Research Fund (Ref: ES/P011020/1).

Acknowledgments: Special thanks to Ya Ping Wang and Keith Kintrea of the University of Glasgow and Deogratius Jaganyi of the University of Rwanda for their comments on an earlier draft. We also thank the three anonymous reviewers for their constructive comments, which helped to improve the manuscript. The authors are solely responsible for the contents of this paper.

Conflicts of Interest: The authors declare no conflict of interest. 


\section{Appendix A}

Interview questions to participants

Q1: What is your understanding when we talk of neighbourhood as a spatial unit?

Q2: From your explanation, what are the neighbourhood typologies in Kigali?

Q3: How do you define the boundaries of these neighbourhoods in practice?

\section{References}

1. UNDESA. $68 \%$ of the World Population Projected to Live in Urban Areas by 2050, Says UN. Available online: https://www.un.org/development/desa/en/news/population/2018-revision-of-world-urbanizationprospects.html (accessed on 3 February 2019).

2. World Urbanization Prospects; The 2014 Revision; United Nations Department of Economic and Social Affairs/Population Division: New York, NY, USA, 2014.

3. Ravallion, M.; Chen, S.; Sangraula, P. New Evidence on the Urbanization of Global Poverty. Popul. Dev. Rev. 2007, 33, 667-701. [CrossRef]

4. Bryceson, F.; Gough, V.; Rigg, J.; Agergaard, J. Critical commentary: The World Development Report 2009. Urban Stud. 2009, 4, 723-738. [CrossRef]

5. Urban Development. Available online: http://www.worldbank.org/en/topic/urbandevelopment/overview (accessed on 23 April 2019).

6. García-Ayllón, S. Rapid development as a factor of imbalance in urban growth of cities in Latin America: A perspective based on territorial indicators. Habitat Int. 2016, 58, 127-142. [CrossRef]

7. Huchzermeyer, M. Cities with Slums: From Informal Settlement Eradication to a Right to the City in Africa; Juta Academic: New York, NY, USA, 2011.

8. Benken, E.E. Nowhere to Go: Informal Settlement Eradication in Kigali, Rwanda; Senior Honors, University of Louisville: Louisville, KY, USA, 2017.

9. Potts, D. Urban Livelihoods and Urbanization Trends in Africa: Winners and Losers?' King's College London, EPD Occasional Paper Series. 2013. Available online: http://www.kcl.ac.uk/sspp/departments/ geography/research/epd/workingpapers.aspx (accessed on 11 October 2018).

10. Grant, R. Globalizing City. The Urban and Economic Transformation of Accra, Ghana; Syracuse University Press: Syracuse, NY, USA, 2009.

11. Murray, M. City of Extremes. The Spatial Politics of Johannesburg. Durham; Duke University Press: Durham, NC, USA, 2011.

12. Manirakiza, V. La Problématique de L'urbanisation Spontanée Face à la Modernisation de la Ville de Kigali (Rwanda). Ph.D. Thesis, Universitaires de Louvain, Leuven, Belgium, 2015.

13. Informal Settlements Choking Kigali City. Available online: https://www.theeastafrican.co.ke/rwanda/News/ Informal-settlements-choking-Kigali-city/1433218-3367628-wjnifiz/index.html (accessed on 15 March 2019).

14. Wakhungu, J.; Huggins, C.; Nyukuri, E.; Lumumba, J. Approaches to Informal Urban Settlements in Africa: Experiences from Kigali and Nairobi; Policy Brief; ACTS: Nairobi, Kenya, 2010.

15. Rwanda Civil Society Platform. Analysis of Land Expropriation and Transfer Process in Rwanda. Final Report; Rwanda Civil Society Platform: Kigali, Rwanda, 2017.

16. Government of Rwanda. National Housing Policy; Government of Rwanda: Kigali, Rwanda, 2015. Available online: www.rha.gov.rw/fileadmin/user_upload/Documents/.../National_Housing_Policy.pdf (accessed on 7 July 2018).

17. Manirakiza, V. Promoting inclusive approaches to address urbanisation challenges in Kigali. Rev. Econ. Fin. 2014, 6, 161-180.

18. Goodfellow, T. Rwanda's political settlement and the urban transition: Expropriation, construction and taxation in Kigali. J. East. Afr. Stud. 2014, 8, 311-329. [CrossRef]

19. Baffoe, G. Understanding the Neighbourhood Concept and its Evolution. Env. Urbaniz Asia 2018, 10, 393-402. [CrossRef]

20. Olowoporoku, O.; Salami, A.; Akintifonbo, O. Assessment of Residents' Neighbourhood Confidence in an African Traditional City: The Abeokuta Experience. Econ. Environ. Stud. 2017, 17, 757-775. [CrossRef] 
21. Park, Y.; Rogers, G.O. Neighborhood Planning Theory, Guidelines, and Research: Can Area, Population, and Boundary Guide Conceptual Framing? J. Plan. Lit. 2015, 30, 18-36. [CrossRef]

22. Bjarnesen, J. The ambivalence of neighbourhood in urban Burkina Faso. Anthro. S. Afr. 2015, 38, 331-343. [CrossRef]

23. Holland, S.; Burgess, S.; Grogan-Kaylor, A.; Delva, J. Understanding neighbourhoods, communities and environments: New approaches for social work research. Br. J. Soc. Work 2010, 41, 689-707. [CrossRef]

24. Kallus, R.; Law-Yon, H. What is a neighbourhood? The structure and function of an idea. Environ. Plan. B 2010, 27, 815-826. [CrossRef]

25. Geyer, H.S., Jr. Evaluating Ecological, Subcultural and Political Approaches to Neighbourhood Change and Neighbourhood Poverty. Hous. Theory Soc. 2018, 36, 189-205. [CrossRef]

26. Martin, D.G. Enacting neighbourhood. Urban Geog. 2003, 24, 361-385. [CrossRef]

27. Bonds, A.; Kenny, J.T.; Wolfe, R.N. Neighbourhood revitalization without the local: Race, non-profit governance, and community development. Urban Geog. 2015, 36, 1064-1082. [CrossRef]

28. Anderson, E. Streetwise: Race, Class, and Change in an Urban Community; University of Chicago Press: Chicago, IL, USA, 1990.

29. Lee, B.A.; Campbell, K.E. Common ground? Urban neighbourhoods as survey respondents see them. Soc. Sci. Q. 1997, 78, 922-936.

30. Getis, A. Analytically derived neighbourhoods in a rapidly growing West African city: The case of Accra, Ghana. Habitat Int. 2015, 45, 126-134. [CrossRef]

31. Haeberle, S.H. People or place: Variations in community leaders'subjective definitions of neighbourhood. Urban Aff. Q. 1988, 23, 616-634. [CrossRef]

32. Kearns, A.; Parkinson, M. The Significance of neighbourhood. Urban Stud. 2001, 38, 2103-2110. [CrossRef]

33. Galster, G.C. What is neighbourhood? An externality-space approach. Int. J. Urban Reg. Res. 1986, 10, 243-263. [CrossRef]

34. Hopkins, E. Understanding the Different Types of Low-Income Neighborhoods. Community Invest. 2016, 22, $13-36$.

35. Jackson-Smith, D.B.; Stoker, P.A.; Buchert, M.; Endter-Wada, J.; Licon, C.V.; Cannon, M.S.; Li, S.; Bjerregaard, Z.; Bell, L. Differentiating Urban Forms: A Neighborhood Typology for Understanding Urban Water Systems. Cities Environ. (CATE) 2016, 9, 5 .

36. Rwanda Environment Management Authority (REMA). State of Environment and Outlook Report; Rwanda Environment Management Authority: Kigali, Rwanda, 2013; 40p. Available online: http://wedocs.unep.org/ handle/20.500.11822/9069 (accessed on 7 July 2018).

37. Uwayezu, E.; de Vries, W.T. Expropriation of Real Property in Kigali City: Scoping the Patterns of Spatial Justice. Land 2019, 8, 23. [CrossRef]

38. National Institute of Statistics of Rwanda (NISR). Rwanda 4th Population and Housing Census; National Institute of Statistics of Rwanda: Kigali, Rwanda, 2012.

39. Twarabamenye, E.; Mukashema, A. Long-run Trend of Cities' Informal Housing: A Solution for the Majority of Kigali Urban Dwellers and a Challenge to Urban Development in Rwanda. J. Environ. Manag. 2012, 3, $35-56$.

40. Shortage of Low-Cost Housing to Continue Biting in Kigali. Available online: https: //www.theeastafrican.co.ke/rwanda/Business/Shortage-of-low-cost-housing-to-continue-biting-inKigali/1433224-2607494-o9vxhjz/index.html (accessed on 24 March 2019).

41. Nduwayezu, G. Modeling Urban Growth in Kigali City. Rwanda J. 2015, 1. [CrossRef]

42. SURBANA. Kigali City Sub-Areas Planning Detailed Master Plan Report for Nyarugenge District; Surbana International: Singapore, 2013.

43. Urban Development: Urban Policies for an Increasingly Urban World. Available online: http://www.oecd. org/governance/regional-policy/urbandevelopment.htm (accessed on 6 April 2019).

44. MINECOFIN. Ministry Finance and Economic Planning; Rwanda Vision 2020; MINECOFIN: Kigali, Rwanda, 2000.

45. MININFRA. Update Version of the National Human Settlement Policy in Rwanda, Ministry of Infrastructure; MININFRA: Kigali, Rwanda, 2009.

46. MININFRA. National Urban Housing Policy for Rwanda; Ministry of Infrastructure: Kigali, Rwanda, 2008.

47. MINECOFIN. EDPRS Rwanda; MINECOFIN: Kigali, Rwanda, 2007. 
48. MINITERE. Rwanda Land Policy; MINITERE: Kigali, Rwanda, 2004.

49. Denzin, N.; Ryan, K. Qualitative Methodology (including focus groups). In The SAGE Handbook of Social Science Methodology; Outhwaite, W., Turner, S.P., Eds.; Sage: Thousand Oaks, CA, USA, 2007; pp. 578-594.

50. Creswell, J.W. Research Design: Qualitative, Quantitative, and Mixed Methods Approaches, 3rd ed.; Sage: Thousand Oaks, CA, USA, 2009.

51. Silverman, D. Doing Qualitative Research, 5th ed.; SAGE Publications Ltd.: London, UK, 2017.

52. Patton, M.Q. Qualitative Research and Evaluation Methods, 3rd ed.; Sage: Thousand Oaks, CA, USA, 2009.

53. Creswell, J.W. Qualitative Inquiry and Research Design: Choosing among Five Approaches, 3rd ed.; SAGE: Los Angeles, CA, USA; London, UK, 2013.

54. Phillippi, J.; Lauderdale, J. A Guide to Field Notes for Qualitative Research: Context and Conversation. Qual. Health Res. 2018, 28, 381-388. [CrossRef] [PubMed]

55. Braun, V.; Clarke, V. Using thematic analysis in psychology. Qual. Res. Psychol. 2006, 3, 77-101. [CrossRef]

56. Kuper, A.; Reeves, S.; Levinson, W. An introduction to reading and appraising qualitative research. BMJ 2008, 337, 404-407. [CrossRef]

57. Miles, B.; Huberman, A.; Saldana, J. Qualitative Data Analysis, 3rd ed.; Sage: Thousand Oaks, CA, USA, 2014.

58. Castleberry, A.; Nolen, A. Thematic analysis of qualitative research data: Is it as easy as it sounds? Curr. Pharm. Teach. Learn 2018, 10, 807-815. [CrossRef]

59. Yin, R.K. Qualitative Research from Start to Finish; The Guilford Press: New York, NY, USA, 2011.

60. SURBANA. Detailed District Physical Plans for Kicukiro and Gasabo Kigali, Rwanda: Vision Report; Draft: May 2012a; Surbana International: Singapore, 2012.

61. Dorier-Apprill, E. Vocabulaire de la Ville; Editions du Temps; Notion et Références: Paris, France, 2001.

62. World Bank. Review and Update of the World Bank's Environmental and Social Safeguard Policies: Environmental and Social Framework; World Bank Group: Washington, DC, USA, 2013.

63. Godana, W.; Mengiste, B. Environmental factors associated with acute diarrhoea among children under five years of age in Derashe district, Southern Ethiopia. Sci. J. Pub Health 2013, 1, 119-124. [CrossRef]

64. Lubaale, G.N.; Musyoki, S.M. Pro-Poor Sanitation and Hygiene in East Africa: Turning Challenges to Opportunities; Paper Presented at the East Africa Practitioners Workshop on Pro-poor Urban Sanitation and Hygiene; LAICO Umubano Hotel: Kigali, Rwanda, 2011.

65. Todes, A. Urban growth and strategic spatial planning in Johannesburg, South Africa. Cities 2012, 29, $158-165$. [CrossRef]

66. Faking it: The Rwandan GDP Growth Myth. Review of African Political Economy. Available online: http://roape.net/2017/07/26/faking-rwandan-gdp-growth-myth/ (accessed on 23 February 2019).

67. Nagdeve, D.A. Environment and Health in India; Paper Presented at the IUSSP Regional Population Conference on 'Southeast Asia's Population in a Changing Asian Context; World Bank: Bangkok, Thailand, 2002.

68. UN-Habitat. Cities and Climate Change: Global Report on Human Settlements; United Nations Human Settlements Programme (UN-Habitat): Nairobi, Kenya, 2011; ISBN 978-1-84971-371-9.

69. Baffoe, G.; Mutisya, E. Social Sustainability: A Review of Indicators and Empirical Application. Env. Manag. Sust. Dev. 2015, 4, 242-262. [CrossRef]

70. Shimamura, Y.; Yang, J.; Baffoe, G.; Dodo, J.; Mwakesi, I.; Matsuda, H.; Kiemo, K.; Mutune, J.; Mutisya, E.; Mungai, D.; et al. Rethinking the Kibera 'Slum': The role of social networks as a mechanism for coping with the increased demand for job opportunities. J. Econ. Sustain. Dev. 2017, 8, 157-169.

(C) 2020 by the authors. Licensee MDPI, Basel, Switzerland. This article is an open access article distributed under the terms and conditions of the Creative Commons Attribution (CC BY) license (http://creativecommons.org/licenses/by/4.0/). 